QUADERNS DE FILOSOFIA VOL. III NÚM. I (20I 6): 5I-69

ISSN: 234I-I4I 4 eISSN: 234I-3042 DOI: IO.7203/QFIA.3.I.7088

Elena NÁJERA

Universidad de Alicante

\title{
El silencio como recurso del individuo en Thoreau y Nietzsche
}

Recibido: 1/9/15. Aceptado: 10/3/16

Resumen: El artículo aborda la reivindicación del silencio en las filosofías de Thoreau y Nietzsche como recurso crítico contra la falta de autenticidad que amenaza al individuo de las sociedades modernas. El trasfondo que confiere significado a la comparación es la voluntad convergente de impugnar, a uno y otro lado del Atlántico, el concepto ilustrado de ciudadanía. Para ello, ambos autores parten de la constatación de las deficiencias expresivas — tanto epistemológicas como, fundamentalmente, éticas - del lenguaje que da voz a la vida pública. Sus respectivos planteamientos les llevarán a una comprensión excéntrica de la filosofía como forma de vida, aunque desembocarán en dos sensibilidades morales diferentes.

Abstract:The article addresses the vindication of silence in Thoreau's and Nietzsche's philosophies as a critical tool against the lack of authenticity that threatens the individual in modern societies. The background for making sense of this comparison is the convergent willingness, in both sides of the Atlantic, to refute the enlightened notion of citizenship. Both authors depart from the observations of the expressive deficiencies —epistemological and, essentially, ethical_ of language that public life enacts. Their respective accounts lead them to an eccentric understanding of philosophy as a form of life, despite their different moral sensibilities.

Palabras clave: Thoreau, Nietzsche, silencio, individuo.

Keywords: Thoreau, Nietzsche, silence, individual. 
$\mathrm{H}$ ABLAR, escribir sobre el silencio no deja de resultar una contradicción pragmática. La actitud más congruente al respecto sería justamente la de abstenerse de cualquier disertación y abandonarse sin más a "ese océano oscuro y luminoso" - tomando prestada la definición de un místico de nuestros días (D’Ors 2OI2, 110)_, que quizás solo pueda plasmarse metafóricamente en una imagen. Sin embargo, los dos autores convocados en las próximas páginas, y que fueron prolíficos escritores, dedicaron cuidadas frases al silencio, aunque, sobre todo, intentaron incorporarlo a su actitud filosófica y reflejarlo en su propia forma de vida. Como queremos mostrar, H. D. Thoreau (1817-1862) y F. Nietzsche (1844-1900) pretenden activar de esta manera un recurso crítico. La renuncia a la palabra es, en efecto, la contrapartida de una crítica al lenguaje que funciona, en última instancia, como una censura a la filosofía moderna y a su ambición de contener la totalidad de la realidad en los límites del discurso. Para ambos, no obstante, el dominio de la experiencia subjetiva se resiste al trazado conceptual y ético que marcan las palabras. De ahí que, tal y como se sugiere en el título, el individuo se conjugue copulativamente con el silencio en un tramo del pensamiento contemporáneo — en el que concurren, además, otros nombres propios ${ }^{1}$ — , interesado no ya en la Verdad, el Progreso o el Bien, sino en el sentido de la existencia.

La reunión de Thoreau y Nietzsche en torno a este tema permite comparar cómo casi coetáneamente - aunque Nietzsche pertenece una generación posterior - uno y otro plantean y elaboran este capítulo de la crisis de la modernidad a ambos lados del Atlántico. En frente del viejo continente, se perfila, en efecto, la juventud de un nuevo mundo que comienza su andadura política y cultural con una Declaración de Independencia y un nuevo texto constitucional y que, consecuentemente, parece prometer una diferencia. Acogiéndonos al tópico hegeliano, si el sol de la historia universal ha dado por completado su recorrido al ponerse en Europa, Norteamérica aparece como un espacio todavía impensado, demasiado movedizo y heterogéneo — dado el constante flujo migratorio - como para prestarse a un concepto. Ha perdido su cultura precolombina, pero, pese a presentarse como un "anejo" del territorio europeo, no es éste sin más: "está aún”, reconoce G. W. F. Hegel, "en trance de formar sus momentos elementales". ${ }^{2}$ En sus Lecciones sobre la filosofía de la historia

${ }^{1}$ Es también el caso de autores como F. Mauthner y L. Wittgenstein. Véase al respecto Nájera, E., "Filosofía y silencio. Las miserias del lenguaje en el fin-de-siècle" (SÁNCHEZ Durá 2008).

${ }^{2}$ Por ello considera Hegel $(\mathrm{I} 997,394)$ que su organización política no puede servir como prueba a favor del régimen republicano: "A la afirmación de que en nuestra época ningún Estado 
universal, en cualquier caso, se resiste a condenarlo a la mera contingencia histórica, concluyendo que quizás pueda ser para los desencantados, "para todos los que están hastiados del museo histórico de la vieja Europa", un país de "nostalgia", de dulces sueños y, en este sentido, insinúa, "el país del porvenir" (Hegel 1997, 169 y ss.). Su importancia histórica se habría de mostrar, a su entender, en tiempos futuros, fuera del suelo en el que hasta ese momento había transcurrido la historia universal. Pero Hegel se impone silencio al respecto — “el filósofo no hace profecías", zanja—, haciendo valer el principio de que la filosofía solo ha de ocuparse de lo inteligible, es decir, de lo "que es y es eterno: la razón" (Ibíd., 177). Y tal vez nuestros dos autores habían igualmente asumido estas reglas de juego y por ello desconfiaban de lo que podían dar de sí las palabras.

También a este lado del Atlántico, Nietzsche comparte la opinión decimonónica de que América es "hija de Europa" y, así, cuando ejerce como crítico de la cultura contemporánea las equipara a veces expresamente. ${ }^{3}$ No obstante, también matiza la convergencia, reconociendo la impresión inaugural, de flamante comienzo, que ofrece el nuevo mundo frente al anquilosamiento del modo de vida europeo. Habida cuenta de lo cual, si en Alemania el análisis de la política está condenado a "estudios históricos", entiende que en Norteamérica es posible hacerlo en vivo: allí "aún se pueden ver con los ojos e investigar los movimientos incipientes y normales del cuerpo social" (NIETZsCHe I986, 206; KSA 2-682).

En el marco de esta época en construcción, Thoreau forma parte, de hecho, de un movimiento filosófico genuinamente americano, el trascendentalismo, que acompaña el recorrido fundacional de los Estados Unidos. ${ }^{4}$ Reciclando el lenguaje del romanticismo y del puritanismo, esta corriente — dando

grande puede ser un Estado libre, suele oponerse el ejemplo de los Estados Unidos de América, en los cuales, se dice, puede verse cómo unos Estados republicanos de gran escala subsisten. Pero esto es insostenible. Norteamérica no puede considerarse todavía como un Estado constituido y maduro. Es un Estado en formación".

${ }^{3}$ Nietzsche 1986, 186; KSA 2-650. Las obras de F. Nietzsche se citarán según la edición Sämtliche Werke. Kritische Studienausgabe in 15 Banden (KSA), 15 vols., Berlín-Nueva York: Walter de Gruyter, 1999 (ed. de G. Colli y M. Montinari), señalándose volumen y página. La correspondencia se citará según la edición Sämtliche Briefe. Kritische Studienausgabe in 8 Banden (KSB), 8 vols., Berlín-Nueva York: Walter de Gruyter, 1986 (ed. de G. Colli y M. Montinari), indicándose, igualmente, volumen y página.

${ }^{4}$ El trascendentalismo norteamericano — que incluiría también los nombres de R. W. Emerson, Theodore Parker, Bronson Alcott, Margaret Fuller y Ellery Channing - no es un desarrollo, a pesar de las apariencias léxicas, de la filosofía trascendental de Kant. El propio Emerson, sin embargo, reconoce el origen kantiano del término "trascendental" que maneja afirmando hacer suya una acepción "popular" del mismo que sanciona la primacía del pensamiento intuitivo, de las ideas, sobre la experiencia. (Véase su ensayo The transcendentalist, EMERson I984, 246.) 
telegráficamente algunas de sus claves - se desarrolla con una firme vocación renovadora en términos antimaterialistas y antitradicionalistas. $Y$ acabará instalándose en una crítica excentricidad socio-política que quedará emblemáticamente ilustrada en la trayectoria del propio pensador de Concord tan interesada en desviarse de la ciudad, de su lógica capitalista y electoralista que, en definitiva, vacía, a su entender, como repasaremos, de moralidad la vida pública.

En la obra de Nietzsche no se registra ninguna cita o reseña de Thoreau. Pero Nietzsche sí se reconoció admirado lector de su maestro R. W. Emerson, a quien llega a distinguir como su "alma gemela". Junto con otros títulos, sus Essays fueron acogidos calurosamente en su biblioteca personal, que contenía una edición alemana de los mismos de 1858 profusamente subrayada y anotada, lo que prueba la familiaridad del pensador alemán con los planteamientos trascendentalistas. ${ }^{6}$ La sintonía se debe a que ambos autores coinciden en su interés por elaborar una ética de la autenticidad, en torno a la que girará así mismo la propuesta de Thoreau, como vamos a ver. En lo que sigue, aunque recurriremos puntualmente a la mediación de Emerson, en tanto y cuanto que es una influencia compartida, propiciaremos el encuentro entre Thoreau y Nietzsche, puesto que ello nos permitirá valorar esa conjunción entre silencio e individuo que nos ocupa sobre el trasfondo que le confiere significado, y que no es otro, como ya se ha sugerido, que la impugnación del concepto ilustrado de ciudadanía. Esta impugnación centraliza la obra thoreauviana y tiene también un despliegue importante en la del filósofo del martillo, lo que facilitará un paralelismo que confluirá en la comprensión de la filosofía como forma de vida, pero que desembocará en dos sensibilidades morales diferentes.

Comencemos, no obstante, presentando la crítica del lenguaje que ambos activan ante sus deficiencias expresivas, que son tanto de carácter epistemológico como, fundamentalmente, ético.

\section{LA CRÍTICA DEL LENGUAJE}

Como hemos señalado, la crítica del lenguaje que le franquea el paso al silencio en Thoreau y Nietzsche llega a la conclusión —antiilustrada, por darle una filiación rápida - de que el discurso no puede apropiarse de la totalidad de la experiencia. Ciertamente, la confianza en el lenguaje natural, como instrumento de inteligibilidad, había ido acusando una erosión paulatina desde

${ }^{5}$ Nietzsche, fragmento 12[68] del otońo de 1881, KSA 9-588.

${ }^{6}$ La biblioteca de Nietzsche también albergaba otros títulos de Emerson como The conduct of life y Letters and social aims, igualmente traducidos al alemán. (VV.AA. 2003, 210 y ss.) 
los mismos albores de la modernidad de la mano de la ciencia (STEINER 2003, 29 y ss.). Esta, a partir del siglo xviI, procede, en efecto, a desvincular una significativa parcela de verdad y de realidad con respecto al predicado verbal. El desarrollo de la matemática, que permite la geometría analítica y la teoría de las funciones algebraicas, así como el cálculo de Newton y Leibniz comienza a dibujar ese abismo entre la cultura humanística y la científica que se abre ya en el siglo xix. Asumiendo este lenguaje universal independiente de las palabras, progresivamente más intraducible a ellas, las ciencias, no solo las formales, sino las empíricas — y, en un envite más reciente, las sociales, cabría añadir-, comienzan a expresarse en un registro antiliterario, podría decirse, que renuncia al hilo discursivo de la narración a favor de la demostración que ofrecen fórmulas, cifras y gráficas.

Esta desautorización científica del lenguaje que se va asimilando culturalmente tiene un correlato filosófico en la negación de la competencia epistemológica de las palabras, algo que Nietzsche sanciona apuntando a su génesis metafórica. ${ }^{7}$ Emerson, en sus Ensayos, ya había recreado ese momento originario como un ejercicio lírico, que descubría el lenguaje como "una especie de panteón de las musas", como "poesía fosilizada" (EMerson 2000, 80-1). Nietzsche elabora paradigmáticamente este planteamiento en su temprano ensayo de 1873 Sobre verdad y mentira en sentido extramoral, según el cual, el primigenio vínculo de nuestro vocabulario con la realidad se cifra en un doble y violento movimiento figurativo en el que los estímulos nerviosos son traducidos a imágenes y éstas, seguidamente, a sonidos. Y en ambos casos se da - advierte — "un salto total desde una esfera a otra completamente distinta" (NietzsChe 2000, 22; KSA 1-879). Tras todo este trabajo hermenéutico, las palabras recogen una operación de abstracción que para Nietzsche se caracteriza por su arbitrariedad. Se constituyen y funcionan como conceptos que obvian, efectivamente, los casos particulares y las diferencias singulares a favor de una especie de arquetipo: "como si en la naturaleza", apunta críticamente, "hubiese algo separado de las hojas que fuese la "hoja" (Ibid., 24; KSA 1-880).

En el diccionario se acumulan, así pues, significados universales cuya vigencia parece deberse a una causa, a algo real. Nuestro vocabulario ampara, en definitiva, una metafísica que sostiene la ilusión de un mundo ideal. Ilusión que se ve reforzada por la propia gramática organizada en los términos de sujeto/predicado. Para Nietzsche (1983, 42; KSA 5-34-5; 1996, 48-9; KSA 6-77), se trata de un "hechizo", de una cuestión de fe parangonable y solidaria con la creencia en Dios que gestiona una determinada interpretación sustancialista

${ }^{7}$ Nietzsche no contempla la posibilidad de retrotraerse al instante cero del lenguaje. Se trata más bien de recrear una génesis filosófica — que no científica— que ilustre su convencionalismo. 
de la realidad. Su clave la encontramos en un pasaje de Crepúsculo de los idolos que insiste en el grosero fetichismo que guía los primeros pasos expresivos del ser humano y que "ve en todas partes agentes y acciones: cree que la voluntad es la causa en general; cree en el "yo», cree que el yo es un ser, que el yo es una substancia, y proyecta sobre todas las cosas la creencia en la substancia-yo - así es como crea el concepto 'cosa'" (Nietzsche i996, 48-9; KSA 6-77).

A entender de Nietzsche, nuestro lenguaje es, en efecto, una traducción del rudimentario esquema voluntarista y animista con el que el ser humano se enfrentó al mundo para hacerlo inteligible a su imagen y semejanza. Por ello, su hechura es irremediablemente antropomorfa. Esta circunstancia, como vamos a ver enseguida, tiene unas implicaciones morales que animarán al silencio, pero nos interesa acabar de sacar primero sus consecuencias epistemológicas. Y es que a esa gran operación hermenéutica que consuman las palabras al servicio de la precaria condición humana — propia de los "seres más infelices, delicados y efímeros" (NIETZSCHE 2000, 18; KSA 1-876) — le corresponde una teoría del conocimiento dispuesta a renunciar a la esencia de las cosas.

Nietzsche lo hace, por su parte, con entusiasmo redefiniendo la verdad en términos literarios como "una hueste en movimiento de metáforas, metonimias, antropomorfismos" que, desde luego, se muestra inútil para el conocimiento (Ibid., 25; KSA 1-880). Nuestro lenguaje, por lo tanto, no tiene rendimiento epistemológico, aunque sí un alto valor expresivo y artístico. El discurso se presta, por ello, a un uso creativo que, sin embargo - y esta es la cuestión decisiva-, no trasluce fácilmente autenticidad en la medida en que recoge un punto de vista impersonal. Por ello, la deficiencia del lenguaje sobre la que nos van a seguir ilustrando Nietzsche y Thoreau tiene que ver con la moral, con el modo de vida que las palabras administran en el dominio de la res publica.

\section{LA EROSIÓN DE LA CIUDADANÍA}

El lenguaje, en efecto, va a quedar definitivamente desacreditado para nuestros autores en el frente ético-político en la medida en que se integra en la rutina democrática de la que se jactan las sociedades modernas. Thoreau ( 1995,105$)$ carga directamente contra el juego "superficial", perverso, de la política electoralista, que mendiga votos para componer una mayoría con la que poder manipular a los ciudadanos. En esta operación, interviene de manera decisiva la opinión pública que se gestiona y controla a través de la prensa. "Los periódicos son el poder dominante", asume, de hecho, en Una vida sin principios (Thoreau 1995, 107). Y en numerosos pasajes de esta y otras 
obras, puede encontrarse una aguda crítica a la merma de la capacidad crítica y expresiva de las palabras que se consuma en este medio y que redunda en la banalización de la realidad. Nuestro autor afirma no haber leído nunca un dato memorable en un periódico, sino solo anécdotas, rumores e incidentes insignificantes llamados a repetirse una y otra vez (ThOREAU 20 io, 141). Los diarios, apunta, "nos dan noticias que un hombre observador, en una caminata solitaria, ni siquiera se detendría a mencionar; como si el aparecer en público les diera algo de importancia y de dignidad" (Thoreau, 2013, 103; I995, 91 y ss.). Thoreau denuncia, en resumidas cuentas, el ruido que hace la trivialidad en la cultura de masas y que amenaza con distraer y saturar y, finalmente, anular la reflexión individual.

En la misma línea, Nietzsche $(2000,26)$ identifica literalmente la opinión pública con la pereza privada, es decir, con la renuncia a tener un criterio propio. A su juicio, la prensa y su lectura generalizada desactiva la tensión del espíritu, la posibilidad del librepensamiento que ha de ser la seńa de los buenos europeos y su defensa contra los discursos nacionalistas que han tomado la palabra en el viejo continente. Fiel a ellos, el estilo periodístico se consolida como el lenguaje característico del estado moderno y, a la altura de la mediocridad que éste amasa, solo sirve a intereses políticos puntuales y a las modas que sacuden la ciudadanía. Por ello, el potencial artístico de las palabras se pierde, se malgasta dando voz a las inercias gregarias que definen la vida en común.

De hecho, para Nietzsche, el lenguaje se ha desarrollado con el fin de cubrir expectativas generales antes que particulares. Responde a la necesidad del ser humano de comunicarse con sus semejantes a fin de escudar la propia debilidad y conjurar la posibilidad de un exceso generalizado de violencia. El lenguaje — apunta en este sentido La ciencia jovial — nace para salvar distancias y unificar criterios, para hacer de "puente" entre unos y otros (NIETZSCHE 200I, 352; KSA 3-592). Se trata, por ello, de una "invención útil", de un mecanismo antropológico que vela por la supervivencia. En este sentido, precisamente, considera Nietzsche que está dominado por el "genio de la especie", obligándonos a reflexionar en términos convencionales. La palabra —insiste en un fragmento póstumo- embrutece y despersonaliza: "la palabra convierte en común lo que no lo es". ${ }^{8}$ Por ello, actúa como agente de los intereses colectivos, ejerciendo una coacción impersonal, niveladora, sobre el pensamiento propio. "El lenguaje", se concluye en Crepúsculo de los idolos, "ha sido inventado solo para decir lo ordinario, mediano, comunicable. Con el lenguaje se vulgariza ya el que habla" (Nietzsche i996, 132; KSA 6-128).

${ }^{8}$ Véase el fragmento 10[60] del otońo de 1887 y también, del mismo período, el 9[106], KSA 12-493 y 395. Estos fragmentos se encuentran traducidos en Nietzsche (2006, 201 y 107, respectivamente). 
Volviendo a Thoreau, cabe apuntar que, acaso persiguiendo ese exilio americano de la utopía que sugería Hegel, podría quizás haber contemplado en su país la posibilidad de un nuevo escenario político e intelectual fuera del agotado recorrido del espíritu absoluto. Su propuesta tiene como telón de fondo, ciertamente, un texto fundacional, el de la joven Constitución americana, que contiene la promesa de los ideales republicanos acuñados al calor de los acontecimientos europeos. Sin embargo, su letra se reescribe sobre el ominoso trasfondo del esclavismo y del militarismo -ilustrado en la guerra con México (1846-1848) — que, en definitiva, acusa el fracaso de la nueva política o, dicho de otra manera, su reincidencia en la falta de moralidad del viejo continente. Thoreau asume que América es el campo de batalla donde se ha de librar la batalla por la libertad, pero insiste en que ésta, para no quedar desvirtuada, no puede entenderse, ni resolverse, en un sentido exclusivamente político porque: "incluso si aceptamos que el americano se ha librado de un tirano político, todavía es esclavo de un tirano económico y moral" (Thoreau i995, 99). Al respecto de esta — podríamos decir- ilustración incompleta, se pregunta el siguiente párrafo de Una vida sin principios:

¿Llamamos a ésta la tierra de los hombres libres? ¿Qué supone ser libres respecto del rey George y seguir siendo esclavos del rey Prejuicio? ¿Qué sentido tiene nacer libres y no vivir libres? ¿Cuál es el valor de una libertad política sino el de hacer posible la libertad moral? ¿Alardeamos de la libertad de ser esclavos o de la libertad de ser libres? Somos una nación de políticos y nos preocupamos solo por una defensa superficial de la libertad (THOREAU I995, 100-1)

En efecto, a Thoreau le preocupa primordialmente, como acabamos de leer, la libertad moral. Por ello, sobre el tablero del superficial y rutinario juego democrático y contrariado ante las exigencias del progreso industrial, nuestro autor acusa sin ambages la inautenticidad que aqueja al modus vivendi occidental: consumismo, obsesión por el lucro y la acumulación de riqueza, dedicación alienante al trabajo y extinción del ocio en el negocio - no hay tiempo de ser "sino una máquina"-: "una vida de locos", en resumidas cuentas, que confunde los medios con los fines y se hunde, como ya se ha apuntado, en la trivialidad (Ibid.).

Desde luego, se trata de un diagnóstico contemporáneo compartido en gran medida por Nietzsche. En La ciencia jovial, por ejemplo, se reprueba el trabajo como "el auténtico vicio del nuevo mundo" que "está comenzando ya a infectar con su salvajismo a la vieja Europa, y a extender sobre ella una sorprendente falta de espíritu" (NietzsCHe 200 I, 311; KSA 3-356). Y más allá de esta referencia trasatlántica, el autor de Así habló Zaratustra, como es bien 
sabido, ejemplifica el estilo de vida moderno con la figura de ese último hombre entregado a un hedonismo fácil y adocenado que solo promueve la mediocridad (Nietzsche I994, 38 y ss.).

\section{EL SILENCIO INTERIOR}

Así las cosas, tal y como hemos repasado hasta aquí, el lenguaje que, dada su hechura hermenéutica, ya no puede reclamar competencia epistemológica, impide así mismo la expresión de la individualidad al dar voz a una superficial cultura de masas, al convertirse finalmente en el instrumento de una ciudadanía desactivada — lamenta Thoreau — y vulgarizada — subraya NietzscheEsta circunstancia pone en evidencia, en cualquier caso, para ambos autores, la dificultad de tematizar, de verbalizar el sentido de la existencia. El filósofo de Concord, ciertamente, encuentra su mundo tan "yermo y prosaico" que acaba viéndolo "hecho más para estar de paso que para ser vivido" (Thoreau 20I3, 94). Aun así, reconoce que "en él vive una criatura tan divina como el ser humano" capaz de "simpatizar con los pensamientos más sublimes" (Ibid.). El autor alemán, por su parte, invoca igualmente la capacidad expresiva de un "animal fantástico" que sabe arroparse con un rico tejido de ilusiones (Nietzsche 200 I, 90; KSA 3-372). Sin embargo, a pesar de esta voluntad creativa —en la que uno y otro perseveraron como los magníficos escritores que fueron- la autenticidad parece condenada finalmente al más íntimo de los monólogos. Emerson $(2000,83)$ ya había advertido que "el curso de las cosas es silencioso", "y no se deja acompañar por 'un parlanchín”". En el silencio —insiste en sus Diarios - debemos "envolver buena parte de nuestra vida porque es demasiado sutil para el lenguaje" (LinscotT i960, ix). Esta se expresa mejor en la mudez que acompaña los sueños, las pasiones, las corazonadas, los sentimientos más excelsos, las emociones más sublimes... (Emerson i 984, 207). Por ello, el sentido elude la mediación léxica — siempre pobre— a favor de la callada inmediatez de la "luz interior" (EMERson 2000, 83).

Para Thoreau, existe igualmente una esencial relación entre el silencio y la realidad personal, privada, del individuo, que es la que quiere salvaguardar. "Hay minas de secretos que se abren todo el tiempo en mi interior", señala (Thoreau 2013,58 ). "Nuestros días más ricos", insiste metafóricamente, "son, a veces, aquellos en los que el sol no luce fuera, sino que lo hace mucho más, dentro de nosotros" (Ibíd., 89). Aquí, afirma, "el silencio no tiene fin" (Ibid., 58), y parece ser que, verdaderamente, las palabras poco pueden hacer para articular este estado de autenticidad que se revela casi incomunicable. "Quizá mi naturaleza es algo secreto", sigue recalcando, para puntualizar seguidamente 
que "otros pueden confesar, explicar; yo no puedo" (Ibid., 154). "Completamente en silencio" — concluye — "permanecerá esta hora, y la siguiente, y siempre" (Ibid., 49). ${ }^{9}$

En el mismo tono, Nietzsche (1996, 132; KSA 6-128) asume que: "Nuestras vivencias auténticas no son en modo alguno charlatanas. No podrían comunicarse si quisieran. Es que les falta la palabra". Este abandono al silencio como última reserva del sentido explica el traslado simbólico de su filosofía a escenarios aislados e inaccesibles: "es vida voluntaria en el hielo y en las altas montañas", relata, por ejemplo, en Ecce homo (NieTzsche i995, 16; KSA 6-258). Implica — escribe en otro momento- "permanecer encerrado en un solitario castillo", "una soledad" — por recordar otra de las fórmulas simbólicas que emplea- "en medio de la más solitaria naturaleza". ${ }^{10}$ Lo que allí encuentra, sin embargo, parece compensar al filósofo: se trata de una "pureza tan extrema" que justifica —añade— la "reluctancia ante los 'seres humanos". ${ }^{11}$ La ausencia de distorsión, de otras voces, se promete entonces reconfortante, el seguro contra el adocenamiento que impone el uso de la palabra.

Igualmente, Thoreau $(2013,49)$ entiende que solo puede encontrarse a sí mismo retirándose "a la buhardilla", asociándose "con las arañas y ratones". Desde el exilio cumplido en la cabaña de la laguna de Walden, del que enseguida hablaremos, se rinde a la incógnita del sentido de la vida — "La vida, ¿quién sabe qué es y qué hace?”, apunta en su Diario (Ibid., 72)—, pero desde una firme convicción que nos dará más argumentos para continuar: la de que "la vida más provechosa de la que la historia ha dejado noticia es el constante apartarse de esta vida sin tener nada que ver con ella; el lavarse las manos observando cuán cruel es" (Ibid., 49).

En resumidas cuentas, nuestros dos autores reivindican para el individuo el derecho a desviarse de la inautenticidad que define el modo de vida moderno, lo que implica un rechazo radical de la vida pública. Recurriendo de nuevo a las imágenes que proporciona Emerson, se trata de vivir "oculto y en estrecha unión con la naturaleza", sin permitirse "entrar en el Capitolio ni en la Bolsa" (Emerson 2000, 89). El filósofo, dice, ha de saber elevarse, cual "hombre alado" a una interpretación de las cosas sub specie aeterni. Lo que esta

${ }^{9}$ El planteamiento de Thoreau confluye con una cierta sensibilidad cultural americana inclinada al silencio voluntario y también a la inacción que se ilustra, por ejemplo, en el cuento Bartleby, el escribiente de su coetáneo H. Melville (Lutz 2006). Aunque desborda los objetivos de este trabajo, cabe mencionar, así mismo, la incidencia del silencio thoreauviano en la obra musical y ensayística de John Cage (Bock 2008).

${ }^{10}$ Carta a Malwida von Meysenbug del 12 de mayo de 1887, KSB 8-69 (Nietzsche i999, 208).

${ }^{11}$ Ibid. 
intempestiva ascensión promete, como leemos en una página de sus Ensayos, es la recuperación del sentido: "Subiré más allá de estas nubes y del aire turbio en que vivo — turbio aunque parezca transparente—- " "eso me reconciliará con la vida [...]. Ya la vida no será ruido” (Ibíd., 77).

\section{EL SILENCIO EXTRAMUROS}

Para Thoreau (1995, 79), desde luego, la claridad existencial se gana al margen de la sociedad, donde es más fácil librarse de las servidumbres de la ciudadanía y no dedicarse al comercio ni "los demás procedimientos habituales para ganarse la vida", que quedan descalificados como desarrollos de la inmoralidad. Se debe vivir "independientemente", insiste, "sin depender más que de uno mismo, siempre dispuesto y preparado para volver a empezar y sin implicarse mucho en negocios" (Thoreau i 999, 45). De acuerdo con esta máxima, la trayectoria de Thoreau se recorta como una existencia reacia a cualquier militancia, replegada voluntariamente de la vida comunitaria para intensificar un contacto con la naturaleza, "la dulce y beneficiosa compañía de la naturaleza", que pone en valor la soledad y vuelve "insignificantes las ventajas imaginadas de la vecindad humana" (Thoreau 20 io, 176). Como es bien sabido, el retiro excéntrico de más de dos años a los "bosques", a una cabaña en las orillas de la laguna de Walden, ofrece la mejor imagen biográfica de esta voluntad de encontrar significado fuera de la "ciudad". ${ }^{12}$

Se trata de ser humanos primero y ciudadanos después, lo que para el autor de Desobediencia civil, implica que el individuo es soberano moralmente. Su crítica exhibe desde el primer momento la vocación de renovación espiritual característica del trascendentalismo a la que más arriba nos referíamos, absolutizando la propia conciencia como única norma ético-política. Apelando a ella, aspira a consumar una impugnación de las instituciones socio-políticas occidentales, fundamentalmente del Estado. Para Thoreau (I999, 32 y ss.), la cuestión decisiva es que sus leyes sujetan a los individuos a una potente acción instrumentalizadora que consigue transfigurarlos en "agentes de la injusticia" sin necesidad si quiera de su consentimiento. Este autor quiere denunciar así la cosificación de quienes creen deber lealtad a las instituciones, pues se convierten en una "masa que sirve al Estado no como seres humanos sino básicamente como máquinas" (Ibid., 32). La clave de esta alienación, que aqueja a todos los sujetos cuyo oficio es públicamente reconocido — carceleros, policías, legisladores, políticos, abogados, ministros, funcionarios...-, pero igualmente

\footnotetext{
${ }^{12}$ Sobre el antiurbanismo presente en la cultura americana, véase White (I967).
} 
a todos los que sufragan solidariamente con sus impuestos - y también con su modo de vida acomodado-, las iniciativas gubernamentales, es la desactivación de la autonomía moral. Esta sería, en definitiva, la servidumbre de un modelo de ciudadanía que vulnera la dignidad porque acaba considerando buenos ciudadanos a unos individuos uniformados que para sus gobernantes "no tienen más valor que caballos o perros" (Ibid., 33). Y que, por ello, ante semejante desproporción y divergencia de intereses, invalida el mismo concepto de representación política: "Hay un grupo de entre nosotros que no está representado", replica Thoreau (1995, 101), lo que hace que los impuestos sean "impuestos sin representación".

En consecuencia, tal y como se concluye en Desobediencia civil, el Estado es el menos indicado para gestionar la moral. Por ello, ante la pregunta " ¿Cómo le corresponde actuar a un hombre ante este gobierno americano hoy?" solo cabe advertir el error del patriotismo y contemplar como única opción moral la resistencia. Se reivindica así el derecho a cancelar la lealtad a las instituciones públicas y a no obedecer las leyes cuando sirvan a causas injustas - "no puedo reconocer ni por un instante", escribe Thoreau (1999, 33), "que esa organización política sea mi gobierno y al mismo tiempo el gobierno de los esclavos"- . El contenido de la idea de "revolución pacífica" que aquí se contempla es justamente esta actitud de abstención e insumisión individuales con respecto a las disposiciones públicas — como dejar de pagar impuestos que capacitan al Estado para cometer actos injustos de violencia ${ }^{13}$ -

Sin embargo, nos interesa avanzar subrayando, como insistiremos al final, que esta revolución, que, sin duda, podría servir para cambiar la sociedad y el mundo, no espera del individuo una reacción enérgica o entusiasta ni una acción positiva. Thoreau no anima a enfrentarse al Estado ni a intentar reformar las instituciones socio-políticas, sino más bien a limitarse a evitar la connivencia. Reclama, en consecuencia, el derecho de cada uno a ampliar personalmente la moral fuera de los intereses públicos —el derecho a la idiotez, podríamos concluir recuperando el significado griego del término-

Aunque en un tono diferente, que incorpora un registro combativo, incluso belicoso, Nietzsche propone también una ética de la singularidad que entrega al individuo incondicionalmente la autoridad para legislar su biografía al margen de los códigos establecidos. Queda al cuidado de cada uno diseñar y gestionar su propia moral que, en definitiva, ha de consistir en el cultivo de uno mismo. Por ello, contra cualquier pretensión de universalismo o abstracción al respecto, exige de la virtud que sea una invención personal, pues, de lo

${ }^{13}$ Algo que, como es bien sabido, el propio Thoreau hizo, lo que le llevó a pasar una noche en prisión como relata en Walden y reproduce en Desobediencia civil. 
contrario, se convierte en un peligro para la idiosincrasia. El propio deber, la meta que cada uno se da a sí mismo, no tiene que confundirse con el concepto de deber en general, que es una invitación a la impersonalidad, una mala ficción, por gregaria, incapaz de hacerse cargo del punto de vista individual. "Que cada uno se invente su virtud, su imperativo categórico", concluye El Anticristo (Nietzsche 1997, 40; KSA 6-177). A pesar de que tal propuesta implica el decidido ejercicio de la voluntad de poder y de que de ésta se puede hacer una lectura con intenciones históricas y políticas, la filosofía de Nietzsche no contiene ninguna teoría de la acción más contundente que el llamamiento a la interpretación original de la propia existencia. El desarraigo respecto a la realidad socio-política, su aborrecimiento de las patrias, y sobre todo de la suya — su deseo de "vivir sobre las montańas, al margen, intempestivos, en siglos pasados o futuros" (NieTzsche 200I, \$377, 394 y ss.; KSA 3-628) — circunscribe el ámbito de su propuesta al silencioso espacio de lo personal, como intentaremos acabar de presentar. Su exilio interior, por otra parte, también se consumó exteriormente, ofreciendo una secuencia de imágenes del mismo ese periplo antigermano por el sur de Europa en busca de un clima cultural diferente que vertebró sus años intelectuales más provechosos.

\section{LA FILOSOFÍA COMO MODUS VIVENDI}

De acuerdo con lo hasta aquí dicho, la contrapartida de la renuncia al ruido de la esfera pública es la reivindicación del silencio de la privada. Este movimiento quiere poner en evidencia que la ética no puede entregarse ni a la política ni al derecho, que se muestran incapaces de asumir las preguntas sobre el sentido y el valor de la existencia. La moral se repliega, entonces, a un individuo que, antes que sentirse representado como ciudadano, reclama el derecho a la autenticidad: el derecho a reconocerse en las normas que él mismo establece y a actuar de acuerdo con el propio criterio de tal manera pueda sentirse reconciliado con su mundo. Esto supone que la tribuna desde la que se ejerce la crítica se traslada del discurso a la propia forma de vida. Ya para Emerson, efectivamente, el significado último del mundo era inefable, pero factible en la medida en que la acción particular podía representarlo. "Aunque seáis mudos", señalaba, "el pensamiento hablará a través de vuestros actos, vuestros modales y vuestros rostros" (EMERSON 2000, 36). Y esto es justamente lo que proponen Thoreau y Nietzsche, que le dan, por ello, expresamente a su escritura una ineludible dimensión autobiográfica. Thoreau (2013, 57-8) define las páginas de su Diario, aunque es una descripción que podría hacerse extensiva al conjunto de su obra, como fragmentos espigados del campo que 
cosecha "en plena acción". Insistiendo en el carácter inefable de su individualidad, en que no puede decir "qué es" - "como tampoco puede hacerlo un rayo de sol veraniego. Lo que soy, soy, y no lo digo"-, concluye que la mejor, en realidad la única, explicación es vivir, "existir" (Ibid., 59). En consonancia con este planteamiento, le concede al ejercicio intelectual un significado eminentemente moral, apremiando a transformarlo en un modus vivendi. La filosofía es, en definitiva, una cuestión estrictamente personal que se transcribe en las propias circunstancias:

Ser filósofo no es solo tener pensamientos sutiles, ni siquiera fundar una escuela, sino amar la sabiduría y vivir de acuerdo con sus dictados una vida de sencillez, independencia, magnanimidad y confianza. Es resolver ciertos problemas de la vida, no solo en la teoría, sino en la práctica (ThoreAu 20io, 71)

Hecho esto, ajustada la vida a los principios que dicta la propia conciencia, no procede hablar más. Thoreau asume así, finalmente, que la crítica sociopolítica más coherente pasa por poder escribir un relato autobiográfico impermeable a las exigencias injustas y embrutecedoras de la ciudadanía. Según este proyecto, el yo es el único que puede, de hecho, en el silencio de su vida privada moralizarse — si se nos permite la expresión — y propiciar únicamente en esta medida la moralización de la sociedad. La ética solo puede arraigar en las conciencias de los individuos, que, en última instancia, son, como señalaba en una de sus obras, "los que pueblan el mundo" (Thoreau i995, 93).

Para Nietzsche, igualmente, la actividad intelectual tiene un innegable trasunto existencial. A su juicio, ciertamente, "uno tiene verdaderamente la filosofía propia de su persona” (NieTzsche 2001, 63; KSA 3-347), lo que, contra la idea de que los pensadores manejan intuiciones impersonales, descubre su obra como su "autoconfesión" y "una especie de mémoires no queridas" (Nietzsche i 983, 25-6; KSA 5-18-9). Según Ecce homo, el libro perfecto es aquel que "demuestra su verdad en el hecho de transcribir una intimidad" y, en este sentido, puesto que se trata, como veíamos, de contenidos casi incomunicables, insiste en que "se carece de oídos para escuchar aquello a lo cual no se tiene acceso desde la vivencia". ${ }^{14} \mathrm{El}$ único criterio de la buena comprensión filosófica sería, en resumidas cuentas, la sintonía intuitiva del lector sobre la base de su propia experiencia.

Sin embargo, a pesar de compartir este planteamiento intimista, autobiográfico, de la filosofía, las respectivas propuestas de Thoreau y Nietzsche desembocan, como anunciábamos al principio, y habrá sido posible entrever

${ }^{14}$ Véase el fragmento 9[115], KSA 12-400, en Nietzsche (2006, 112 y I995, 57; KSA 6-300). 
ya al hilo de lo expuesto y de las citas leídas, en dos sensibilidades éticas muy diferentes con cuyo esbozo nos gustaría acabar. Ofrecen sendas narrativas de la autenticidad, en las que se rastrean, tal y como hemos estado viendo, las huellas de Emerson. Este hace, ciertamente, una llamada a la autonomía, a la confianza en uno mismo y a la originalidad que cristaliza en lemas individualistas perfectamente compatibles con las propuestas que hemos repasado, tales como "I make my circumstance" o "Insist on yourself; never imitate". ${ }^{15}$ Sin duda, estos lemas recogen fielmente un rasgo de la idiosincrasia cultural americana, que el propio Hegel entraba a valorar como un exceso de subjetivismo. Reina allí, censuraba, el capricho del sentimiento: "el mayor desenfreno de las imaginaciones" que hace que "cada cual pueda tener su propia concepción del mundo y, por tanto, su propia religión". Los estadounidenses se entregaban a intereses particulares, lo que, a entender del autor de la Fenomenología del Espiritu, suponía una grave deficiencia desde el punto de vista de la eticidad que tenía como contrapartida el desarrollo de una "legalidad sin moralidad". ${ }^{16}$

La cuestión es que Nietzsche, por su parte, también critica la versión americana del ideal de la autenticidad, pero no porque deduzca que falte al sentido de lo universal, sino, todo lo contrario, porque considera que se trata de una versión débil a la medida de la uniformidad democrática que él quiere sortear. Así se reseña en La Ciencia jovial "esa creencia norteamericana actual" que amenaza con convertirse cada vez más en una creencia europea:

el individuo se convence de ser capaz casi de todo, de adoptar cualquier papel; aquí todo el mundo experimenta consigo mismo, improvisa, ensaya de nuevo, ensaya con gusto; aquí toda naturaleza cesa y se convierte en arte (NIETZsChe 200 I, 355-6; KSA 3-596)

El individualismo que aquí se censura es el que se desarrolla ligado a la igualdad, el gran prejuicio moderno que se habría reciclado en el nuevo continente. Se trataría, por tanto, de un individualismo espurio, horizontal - y que opera, según Nietzsche, también en el socialismo y al anarquismo-, que está interesado únicamente en la independencia con respecto a la totalidad, a las instituciones sociales, "se trate del estado o de la iglesia". ${ }^{17}$ De su mano, no sería posible, lamenta, la construcción de una "sociedad en el viejo sentido de la palabra", es decir, de una sociedad en la que tuviera cabida "el aristocratismo

${ }^{15}$ Véanse los ensayos de Emerson The Transcendentalist y Self-reliance (I984, 243 y 199, respectivamente).

${ }^{16}$ Hegel, G. W. F., Lecciones sobre la filosofia de la historia universal I, 169 y ss.

${ }^{17}$ Fragmento 10[82] del otońo de 1887, KSA 12-502-3. 
de los sentimientos", un pathos de la distancia, que permitiera apreciar verticalmente la diferencia inconmensurable que hay entre un ser humano y otro en el desempeño de la autenticidad (Nietzsche 200 i, 357; KSA 3-597).

En cualquier caso, la filosofía de Nietzsche es un ejercicio de intempestividad contra la incomprensión que le deparaba un presente impregnado de ideales gregarios - y en este sentido quedarían equiparados, a su entender, la Ilustración y el nacionalismo: los buenos europeos apunta "no amamos a la humanidad; por otra parte, tampoco somos ni de cerca bastante "alemanes", tal como se entiende hoy la palabra "alemán», como para apoyar el nacionalismo y el odio de razas" (Nietzsche $1983, \$ 256 ; K S A 5-201$ )—. Por ello, se incluía entre "los sin patria", entre aquellos que no pueden acomodarse de ninguna manera a los diferentes patrones ético-políticos de la modernidad:

No "conservamos" nada, tampoco queremos regresar a ningún pasado, no somos de ninguna manera "liberales", no trabajamos por el "progreso", no requerimos taponar en primer término nuestros oídos frente al canto del futuro de las sirenas del mercado - lo que ellas cantan, "iguales derechos", "sociedad libre”, "no más señores y no más esclavos”, ¡no nos seduce!; no consideramos en absoluto como deseable que se funde sobre la tierra el reino de la justicia y la concordia (puesto que bajo todas las circunstancias se convertiría en el reino de la más profunda mediocridad niveladora y chinería) (NiETzsche 200 I, \$377, 394 y ss.; KSA 3-628)

Habida cuenta de esta absoluta falta de sintonía con su época, Nietzsche (Ibid., 395 y i 995, 55) se sentía más bien como "un hijo del futuro", asumiendo un solitario destino como "autor póstumo" y quedando a la espera de unos futuribles "lectores predestinados" que pudieran tener oídos y manos para sus verdades. En este sentido, llega a confesar que no escribe sino para sí, deslizándose al hilo de ello una voluntad de limitar el acceso a su filosofía, una apología de la incomprensión. "Todo espíritu y gusto más distinguido busca elegir también a sus lectores, cuando quiere comunicarse; una vez que los elige, levanta a su vez las barreras contra los otros" (NIETZSCHe 200 I, \$381, 400 y ss.; KSA 3-633). Aquí se pone en juego una determinada política de la escritura y de la lectura - que apenas tenemos tiempo de nombrar-, que hace del estilo una medida que prohíbe una comprensión indiscriminada. Emerson, en cualquier caso, ya había distinguido la incomprensión como "inherente a la grandeza" y, en la misma línea, Nietzsche la encaja como un mérito de los mejores filósofos: "no somos comprendidos jamás" — dice— "y de ahí nuestra autoridad". ${ }^{18}$

${ }^{18}$ Véase, respectivamente, Emerson (1984, 183) y Nietzsche (1996, 31; KSA 6-61). 
El planteamiento de Thoreau no se compagina, en cambio, con este individualismo aristocrático $\mathrm{y}$, a modo de conclusión, nos gustaría medir la divergencia con una pequeña digresión a propósito de la vocación dialógica de las propuestas morales de nuestros dos autores.

\section{A MODO DE CONCLUSIÓN: SILENCIO Y MORALIDAD}

Al igual que Nietzsche, Thoreau, resintiéndose también del desajuste que experimenta con respecto a sus coetáneos, expresa una voluntad póstuma: "podría decirse", escribe en este sentido, "que aún no he nacido", que "la sociedad para la que se me hizo no está aquî" (Thoreau 20I3, 111). Su retiro a los bosques, como hemos tenido ocasión de evocar, ilustra la búsqueda de una forma de vida alternativa que se niega a colaborar con un sistema económico inicuo y a ser partícipe de una organización política que comete atrocidades como la guerra. La moral se instala, en consecuencia, como hemos visto, en el espacio inviolable del propio juicio: "Si un hombre piensa con libertad, sueña con libertad e imagina con libertad, nunca le va a parecer que es lo que no es, y ni los gobernantes ni los reformadores ineptos podrán en realidad coaccionarle" (Thoreau i 999, 53-4). Sin embargo, la profesión de autenticidad que acompaña este gesto conserva una sensibilidad igualitaria y un cierto sentido de la justicia. La reivindicación pacifista que la acompaña sería una buena muestra de ello, aunque para tramitarla se invite — dando una profunda e insuperable muestra de desencanto- a abandonar la ciudad y a renunciar al intento de cambiarla.

La dejación de activismo busca, en resumidas cuentas, ampliar el espacio de la particularidad: "No vine al mundo para hacer de él un buen lugar para vivir", apunta, "sino a vivir en él, sea bueno o malo" (Ibid., 41). Por ello, insiste: "Ahora que la república — la res-pública — está instituida, es hora de buscar la res-privata - los asuntos privados- para cuidar de que, como el senado romano aconsejaba a sus cónsules: ne quid res-privata detrimento caperet, los asuntos privados no sufran deterioro alguno" (Thoreau i 995, 99). Pero Thoreau considera importante entregarse a los propios asuntos con la conciencia tranquila, sin abandonar los principios. En este sentido discurren las siguientes líneas de Desobediencia civil:

Por supuesto, no es un deber del hombre dedicarse a la erradicación del mal, por monstruoso que sea. Puede tener, como le es lícito, otros asuntos entre manos; pero sí es su deber al menos, lavarse las manos de él. Y si no se va a preocupar más de él, que por lo menos en la práctica no le dé su apoyo. Si me entrego a 
otros fines y consideraciones, antes de dedicarme a ellos, debo, como mínimo, asegurarme de que no estoy pisando a otros hombres. Ante todo debo permitir que los demás puedan realizar sus propósitos (Thoreau i999, 38)

El individualismo de Thoreau, así pues, pretende ser una opción moral al alcance de todos y de alcance para todos. El texto ya citado que recoge el paréntesis de su experiencia de retiro — Walden, publicado en 1854- está escrito en una rigurosa primera persona del singular que, aun así, pretende ser ilustrativa, edificante en algún sentido, para esos conciudadanos de los que se ha excluido. Declara estar dispuesto a decir algo sobre su forma de vida, es decir, sobre "si es necesario que sea tan mala como es, si puede mejorar o no" (Thoreau 20io, 62). La buena escritura pasa por "obedecer a la conciencia", por "escuchar con reverencia la voz interior" (ThOREAU 20I3, 54-5), pero un libro es "verdadero", concluye, cuando resulta

íntimo y familiar a todos los hombres. Como el sol en su cara. Como la palabra que se dice casualmente al compañero en verano en el bosque, y ambos permanecen callados (Ibid., 61)

Para Thoreau - y con esta apreciación acabamos, aspirando a condensar la clave de la distancia con respecto a Nietzsche en una lacónica fórmula que nos permita suspender con cierta coherencia las palabras en estas páginas volcadas - es posible, y deseable, compartir el silencio. 


\section{BiBLIOGRAFÍA}

Bock, J. 2008, Concord in Massachussets, Discord in the Word: the Writings of Henry Thoreau and John Cage, Nueva York: Lang.

D'Ors, P. 201 2, Biografía del silencio, Madrid: Siruela.

Emerson, R. W. I984, Selected Essays, Nueva York: Penguin.

Emerson, R.W. 2000, Escritos de estética y poética, Málaga: Analecta Malacitana.

Hegel, G. W. F., Lecciones sobre la filosofía de la historia universal I, 1997, Barcelona: Altaya.

Linscott, R. N. (ed.) i 960, The journals of R. W. Emerson, Nueva York: Modern Library.

Lutz, T. 2006, Doing Nothing: A History of Loafers, Loungers, Slackers, and Bums in America, Nueva York: Farrar, Straus and Giroux.

Nietzsche, F. I983, Más allá del bien y del mal, Barcelona: Orbis.

Nietzsche, F. 1986, Humano demasiado humano II, Madrid: Akal.

Nietzsche, F. 1994, Asi habló Zaratustra, Madrid: Alianza Editorial.

Nietzsche, F. I995, Ecce homo, Madrid: Alianza Editorial.

Nietzsche, F. I996, Crepúsculo de los idolos, Madrid: Alianza Editorial.

Nietzsche, F. 1996, Sämtliche Briefe. Kritische Studienausgabe in 8 Banden, Berlín-Nueva York: Walter de Gruyter.

Nietzsche, F. I997, El Anticristo, Madrid: Alianza Editorial.

Nietzsche, F. I999, Epistolario, Madrid: Biblioteca Nueva.

Nietzsche, F. I999, Sämtliche Werke. Kritische Studienausgabe in 15 Banden, Berlín-Nueva York: Walter de Gruyter.

Nietzsche, F. 2000, Sobre verdad y mentira en sentido extramoral, Madrid: Tecnos.

Nietzsche, F. 2000, Schopenhauer como educador, Madrid: Biblioteca Nueva.

Nietzsche, F. 200 I, La ciencia jovial, Madrid: Biblioteca Nueva.

Nietzsche, F. 2006, El nihilismo europeo. Fragmentos póstumos (otoño, 1887), Madrid: Biblioteca Nueva.

Sánchez Durá, N. (ed.) 2008, Cultura contra civilización. En torno a Wittgenstein, Valencia: Pre-Textos.

Steiner, G. 2003, Lenguaje y silencio, Barcelona: Gedisa.

Thoreau, H. D. I995, Una vida sin principios, León: Universidad de León.

Thoreau, H. D. I999, Desobediencia civil y otros escritos, Madrid: Tecnos.

Thoreau, H. D. 20io, Walden, Madrid: Cátedra.

Thoreau, H. D. 201 3, El Diario (1837-1861), Madrid: Capitán Swing Libros.

VV.AA. 2003, Nietzsches persönliche Bibliothek, Berlín-Nueva York: Walter de Gruyter.

White, M. y L. I967, El intelectual contra la ciudad. De Thomas Jefferson a Frank Lloyd Wright, Buenos Aires: Ediciones Infinito. 